\title{
ESTRATEGIAS NARRATIVAS DE DISEÑO DEL ESPACIO COMO MEDIO DE REPRESENTACIÓN Y CRÍTICA SOCIAL: BARCELONA EN LOS MARES DEL SUR DE MANUEL VÁZQUEZ MONTALBÁN
}

\author{
José R. VALLES-CALATRAVA \\ Universidad de Almería
}

\section{Resumen}

Este artículo analiza las estrategias de representación de la realidad social mediante el diseño del espacio narrativo en Los mares del sur de Manuel Vázquez Montalbán (1979). Para ello, el artículo examina la presentación de Barcelona como ubicación urbana y organización topográfica, aplica los conceptos de cronotopo y de mapa cognitivo individual y social y estudia sucesivamente los lugares, ámbitos de actuación y espacios discursivamente construidos de esta ciudad.

Palabras clave: espacio narrativo, cronotopo, mapa social cognitivo, novela policiaca, novela española contemporánea, Vázquez Montalbán.

\section{NARRATIVE STRATEGIES FOR THE DESIGN OF SPACE AS A MEANS OF REPRESENTATION AND SOCIAL CRITICISM: BARCELONA IN LOS MARES DEL SUR BY MANUEL VÁZQUEZ MONTALBÁN}

\section{Abstract}

This article analyzes the strategies of representation of social reality through the design of the narrative space in Los mares del sur by Manuel Vázquez Montalbán (1979). To this end, the article examines the presentation of Barcelona as an urban location and topographic organization, it applies the concepts of chronotope and individual and social cognitive map, and it successively studies the places, areas of performance and discursively constructed spaces of this city.

Keywords: narrative space, chronotope, cognitive social map, detective novel, contemporary Spanish novel, Vázquez Montalbán. 


\section{UNA INVESTIGACIÓN CRIMINAL Y SOCIOECONÓMICA EN BARCELONA Y EN LA TRANSICIÓN A LA DEMOCRACIA}

Se considera en general Tatuaje, de 1974 (primera novela criminal protagonizada por el detective privado barcelonés Pepe Carvalho, que ya había aparecido dos años antes como agente de la CIA en Yo maté a Kennedy, una obra más de política ficción y experimental que de espionaje y clásica), el relato fundacional de la novela criminal ${ }^{1}$ española moderna, coincidente aproximadamente en su aparición con el fin del franquismo y el inicio de la transición a la democracia. Pero fue en realidad Los mares del sur, de 1979, tercera obra de este tipo de Manuel Vázquez Montalbán ${ }^{2}$ (1939-2003), la que lo encumbró no solo como el principal escritor de esta clase de ficciones -autor de 23 libros $^{3}$-, sino también como su máximo referente, teórico y defensor: director de la revista Gimlet, conferenciante e informador destacado respecto al tema, máximo exponente

${ }^{1}$ Frente a la denominación hispánica más común de novela policiaca/policial, procedente del francés roman policier, prefiero emplear la de novela criminal (que englobaría las dos tendencias básicas de novela enigma y novela negra, ambas con sus respectivas modalidades de relato de investigador y de delincuente), sobre todo por su mayor idoneidad tanto temática como architextual respecto a las narraciones que incluye, pero también por su ya cierta tradición terminológica no solo en la crítica inglesa o alemana, sino asimismo en la hispánica (Coma, Gubern, Padró, Rivero, Valles, Vázquez de Parga, etc.)

${ }^{2}$ El polifacético y prolífico autor fue, además de poeta y novelista, ensayista y periodista, intelectual y político, aficionado a la gastronomía y el fútbol. Cabe destacar entre su muy abundante y variada producción literaria: en poesía -incluido en la antología de Castellet de los novísimos-, Memoria y deseo de 1986 (compilación de su obra lírica hasta ese momento, con Una educación sentimental, Cancionero general: 1939 a 1971 y A la sombra de las muchachas sin flor entre otras); en narrativa, Recordando a Dardé y otros relatos de 1969, Yo maté a Kennedy de 1972, El pianista de 1986, Galíndez de 1990 y Autobiografía del general Franco de 1992, una novela biográfico-política que desmonta el relato oficial de Franco y del franquismo; en ensayo, Informe sobre la información de 1963, Crónica sentimental de España de 1971, ¿Qué es el imperialismo? de 1976 y Mis almuerzos con gente inquietante de 1985. Como periodista firmó numerosos artículos en periódicos y revistas como El periódico, Mundo obrero, Interviú, Por favor, Triunfo y El País, incluyendo revistas literarias como Camp de l'arpa y Gimlet (sobre novela negra y en homenaje al combinado que tomaba Marlowe en The Long Goodbye de R. Chandler).

${ }^{3}$ Tatuaje, La soledad del manager, Los mares del sur, Asesinato en el Comité Central, Los pájaros de Bangkok, La rosa de Alejandría, El balneario, Historias de fantasmas, Historias de padres e hijos, Tres historias de amor, Historias de política ficción, Asesinato en Prado del Rey y otras historias sórdidas, El delantero centro fue asesinado al atardecer, Historias de fantasmas, El laberinto griego, Sabotaje olímpico, El hermano pequeño, Roldán, ni vivo ni muerto, El premio, Quinteto de Buenos Aires, El hombre de mi vida, Milenio Carvalho I: Rumbo a Kabul y Milenio Carvalho II: En las antípodas. 
autoral para la crítica internacional y otros practicantes europeos y nacionales del género en España, con versión de muchas de sus obras al cine y la televisión, etc.

La concesión a esta novela del Premio Planeta de 1979 -el mejor dotado de España; según la crítica de entonces (Conte, 1979), con ocho millones de pesetas y 153.000 ejemplares de tirada-, fue doblemente importante y simbólica: de una parte, architextualmente, por el espaldarazo dado a un género como el criminal (Sánchez Zapatero y Martín Escribà, 2017: 56) que había tenido en el siglo XX escasa-pero no nula- tradición, cultivo y reconocimiento en España ${ }^{4}$; de otro lado, políticamente, porque su ganador era un reconocido intelectual y político antifranquista, en un momento en el que, cuatro años después de la muerte de Franco en noviembre de 1975 y dos antes del intento de golpe de Estado de febrero de 1981, la transición a la democracia vivía uno de sus momentos más tensos, inestables y difíciles. De hecho, además de un homenaje gastronómico a la cultura popular y la identidad colectiva (Colmeiro, 1994: 87), en gran medida y como siempre ha indicado su propio autor, el ciclo criminal protagonizado por Carvalho -correspondiente a la modalidad estadounidense de la hard boiled novel- es justamente un retrato realista y fuertemente crítico, localizado esencialmente en Barcelona, del periodo de la transición española a la democracia (Valles, 1991: 173 y 177; Sánchez Zapatero y Martín Escribà, 2017: 57; Padró, 2018: 29).

La obra, cuyo paratexto titular se basa en el mítico viaje y deseo de alejamiento de la sociedad occidental de Gauguin en su marcha a los mares del sur, narra la investigación por Carvalho del asesinato de un multimillonario -que aparece muerto en un solar en construcción-, cuya principal ilusión era desclasarse reviviendo el mito de Gauguin y abandonándolo todo, y reconstruye su último año de vida, pasado en un barrio obrero ocultándose y trabajando como contable, su amor por una joven trabajadora y su asesinato a navajazos a manos del hermano y unos amigos de la joven que intentaban vengar el deshonor familiar provocado por el embarazo de la muchacha.

\footnotetext{
${ }^{4}$ Sobre el desarrollo histórico y escritural del género en España durante el siglo XX (etapas, características y particularidades, autores y seudónimos, obras y colecciones, etc.), de improcedente síntesis aquí, remito a Vázquez de Parga (1981) y, sobre todo, a Valles (1991).
} 
La novela tiene una doble estrategia intranarrativa de escritura y lectura, significativa e interpretativa, que liga a los últimos responsables internos de la misma: en cierto modo y desde lógicas teóricas distintas, a las figuras intratextuales denominadas implied author e implizite leser respectivamente por Booth (1974) e Iser (1987). Junto a y sobre la organización narrativa de los actores, acontecimientos, momentos y lugares, que permite leer el contenido del discurso, lo relatado en el relato, como una investigación detectivesca progresiva de un crimen previo y reconstruible, se alinea otra estrategia intranarrativa de significación y lectura implícita que diseña y comprende personajes, acción, tiempo y espacio como elementos simbólicos que trasponen y referencian ficcionalmente, en esa narrativa-crónica y crítica antes mencionada que constituye todo el ciclo criminal de Carvalho, la realidad socioeconómica, cultural y política del periodo español denominado de transición a la democracia.

Como novelas, novelas cortas y relatos finalmente inscritos en una larga serie (Sánchez Zapatero y Martín Escribà, 2017: 56-64) que se atiene por tanto a la dialéctica continuidad/novedad, esta ofrece siempre, cronológicamente ordenada y en cada obra, una evolución temporal, ambiental, actoral y sobre todo temática. Pero mantiene asimismo una serie de constantes (retrato social y realismo crítico, tono desengañado, escéptico y cuestionador, lenguaje culto con ciertos accesos al lirismo en las narraciones contrastando con los coloquialismos, catalanismos, exabruptos y términos de la germanía presentes en ciertos diálogos, abundancia de referencias intertextuales literarias y culturales, presencia de actores recurrentes -Carvalho, Biscúter, Charo, Bromuro- y ficcionalización de personajes existentes en el mundo físico, etc.), entre las cuales son sin duda el propio protagonista y la ciudad, Carvalho y Barcelona, las más permanentes y significativas. Crónica sociopolítica, alternativa y crítica, de la versión oficial de un tiempo nacional -la transición española-, el ciclo criminal de Vázquez Montalbán es sin duda, también y paralelamente, crónica urbana (Barcelona) y crónica imaginaria subjetiva (Carvalho: un detective y exespía, culto pero quemalibros, solitario pero solidario ${ }^{5}$ ) de unas andanzas y proceder, ideas y gustos, extraños y personales, atractivos y sugerentes.

${ }^{5}$ El personaje de Pepe Carvalho ha sido quizás el más estudiado por la crítica especializada en la narrativa criminal española. Nacido en 1972 en la novela de espías Yo 


\section{EL DISEÑO SIMBÓLICO DEL ESPACIO COMO ELEMENTO DE REPRESENTA- CIÓN Y CRÍTICA SOCIAL EN LOS MARES DEL SUR}

Frente a la trascendencia para la acción narrativa de los espacios interiores en la novela de tipo enigmático, la serie negra privilegia en general, no ya solo los exteriores, sino el medio urbano en sí mismo (Valles, 1991: 62-64; Colmeiro, 1994: 55; Sánchez Zapatero y Martín Escribà, 2017: 35-39): la ciudad no es solo, narrativamente, el lugar, ámbito de actuación y espacio de trabajo, movilidad e itinerancia del detective -o del criminal-, el espacio inestable de la investigación frente al vivencial, privado y domiciliario (Balló y Pérez, 2005 :37 y 39), sino asimismo la dimensión en la que se muestran las contradicciones sociales contemporáneas y el crimen como síntoma del sistema (Valles, 1991: 63). Y en todo el ciclo criminal protagonizado por Carvalho esa es, asimismo y en general, la doble función de la capital catalana, que muchas veces permite otros emplazamientos alternativos nacionales (Madrid, Albacete, Tenerife, Murcia, etc.) o internacionales (Buenos Aires, Bangkok, Ámsterdam, Kabul, etc.), pero en un papel usualmente más secundario y accidental, menos trascendente y recurrente. Es también el caso concreto de Los mares del sur, obra en la que el espacio en general y Barcelona y los emplazamientos e itinerarios de sus personajes principales por la misma en particular (Padró, 2018: 30-35) cobran una trascendencia enorme, tanto en su dimensión puramente intratextual como socialmente representativa y crítica.

\footnotetext{
maté a Kennedy, su primera aparición detectivesca es de 1974, con Tatuaje, y se extiende por la serie antes citada durante treinta años, hasta 2004, con Milenio, I y II. Caracterizado físicamente como "alto, moreno, treintañero, algo desaliñado» y autocaracterizado como «un expoli, un exmarxista y un gourmet» en su primera aparición (Vázquez Montalbán, 1974: 21 y 193), poca prosopografía más se encuentra en sus aventuras, que sí inciden y perfilan más su perfil psicomoral, social y profesional: escéptico y desengañado, distanciado y crítico, hedonista y reflexivo, culto y quemalibros, expoli y exmarxista, solitario y buen amigo, detective y cocinero... En una entrevista a Víctor Claudín de 1979 el propio autor lo definía y filiaba architextualmente como «un personaje un poco extraño, distanciado [...], investigador privado en la tradición de los tipos creados por la novela americana, el tipo central de Chandler, Hammett o MacDonald» (Valles, 1991: 174).
} 
2.1. La Barcelona negra ${ }^{6}$. Cronotopo y lógica narrativa de la historia: la jungla del asfalto en momentos de injusticia

En relación tanto a este propio relato como a su carácter architextual de género negro, hay dos asociaciones que perfilan dos de las características espaciales configuradoras y delimitadoras de esta modalidad temática.

Primeramente, en la asociación de las respectivas actividades de ubicación espacial y cronológica de espacio y tiempo, lugar y momento pueden vincularse globalmente -fusionarse artísticamente en términos del creador del concepto, Bajtín (1989: 237), que aludía al mundo de lo maravilloso en el tiempo de la aventura para referirse a la novela caballeresca- para crear un cronotopo particular que diferencia a todo el género negro: lo que cabría denominar aquí -usando la imagen del título de W.R Burnett The Asphalt Jungle- la jungla del asfalto en momentos de injusticia sería una integración tempoespacial, metafórica y general, que entiendo que representa bien uno de los aspectos esenciales de la modalidad novelística negra, que suele presentar un universo urbano contemporáneo desordenado y marcado por el crimen como consecuencia de su propia injusticia socioeconómica (deshumanización, corrupción, capitalismo, ambición, etc.). Dice Carvalho en su primera aparición: «Los detectives privados somos los termómetros de la moral establecida, Biscúter. Yo te digo que esta sociedad está podrida. No cree en nada» (Vázquez Montalbán, 1974: 46).

$\mathrm{Y}$, en segunda instancia, la combinación de las respectivas actividades situacionales y actanciales de espacio y personaje, la citada recurrencia topográfica de la ciudad de Barcelona, junto a la itinerancia y movilidad del sujeto-protagonista investigador, contribuyen a crear la dimensión urbana antes comentada (Valles, 1991: 63) que constituye en cierto modo un topos que caracteriza no solo a Los mares del sur sino a toda la tendencia narrativa. En el mismo, crimen/desorden, justicia/orden, criminal/fugitivo e investigador/perseguidor -según los correlatos se muestren en una respectiva codificación hermenéutica/proairética (Barthes, 1980)-, los cuatro grandes seres o fuerzas que, en distintas lógicas narrativas actanciales se alinean y configuran de formas diversas para

\footnotetext{
${ }^{6}$ Imitaré a Vázquez Montalbán (2004) al analizar el espacio de esta novela en distintas Barcelonas.
} 
representar modalidades narrativas criminales específicas, también cobran en esta obra, como en otros relatos negros de investigador -hard boiled novel-, su dimensión simbólica social: un planteamiento de la justicia alejado de la ley/norma y cercano a una visión ético-moral de la misma; una mostración del crimen como un síntoma del desorden social y su consecuente reposición parcial o nula, nunca total; un investigador (protagonista/sujeto: detective privado) no solo especial y distinto del resto de personajes sino alejado de las justificaciones ideológicas y dinámicas financieras del sistema; unos criminales (antagonistas/oponentes) que representan con su actuación delictiva (venganza, honor) no solo móviles humanos sino comportamientos provocados o conformes con el sistema social (Valles, 1991: 73-78). Se aprecian además una investigación más dinámica e itinerante que interpretativa y racional, una actuación menos neutral o alineada con el sistema y más escéptica, cuestionadora e incluso crítica respecto al mismo; y en términos de Bajtín (1986; 1989: 237-409), cabría hablar también de una organización discursiva más dialógica y democrática de las voces y pensamientos de los distintos personajes respecto a la primacía monológica del discurso del detectiveprotagonista de la novela-enigma: subordinante y primordial, racional y aclaratorio.

\subsection{Los lugares de Barcelona. La ciudad como topografía y como mapa cognitivo social: emplazamientos ${ }^{7}$}

Concibo los lugares, dentro de un primer nivel de funcionamiento del espacio en el texto narrativo, como emplazamientos topográficos -naturales o políticos, simbólicos o físicos, exteriores o interiores, rurales o urbanos, centrales o periféricos, etc.- que acogen y ubican hechos y seres o sus representaciones funcionales y lógicas (actantes, funciones)

\footnotetext{
${ }^{7}$ Dado que el estudio del funcionamiento del espacio en un texto narrativo concreto requiere un modelo teórico y un planteamiento metodológico que guíen el análisis concreto, me apoyaré en Zoran (1984) y especialmente en Valles (2008: 178-198), que parte de la distinción de tres estratos textuales (fábula, trama, relato) y las consiguientes ordenaciones respectivas de los hechos (cronológica, narrativa, discursiva) para hacerlos corresponder, en tres respectivas dimensiones (funcional, escénica, verbal), con tres planos espaciales en el texto (situacional, actuacional, representativo), en los que se producen tres actividades espaciales específicas (localización, extensión espaciotemporal, diseño o configuración espacial) que se ligan a tres unidades espaciales concretas (lugar, ámbito de actuación, espacio).
} 
(Weisgerber, 1978: 9; Valles, 2008: 188-189). Hay en la novela numerosos y sucesivos lugares concretos de Barcelona -marco general e inclusivo, como clave architopográfica, del relato- que van acogiendo distintos emplazamientos espaciales de la acción narrativa: desde la discoteca, el automóvil Citroën CX -el zequis-y el solar abandonado de la Trinitat donde el Bocanegra encuentra el cadáver del financiero muerto a cuchilladas en la secuencia ${ }^{8}$ inicial, hasta la cocina, el salón, el sótano y el jardín de la casa de Vallvidrera en la que Carvalho halla degollado el cadáver de la perrita Bleda en la secuencia final (Vázquez Montalbán, 2018: 39-46 y 284-285), se suceden numerosos emplazamientos, bien profesionales y vitales -privados y cerrados-del detective (su despacho junto a la Rambla de Santa Mónica y su casa de Vallvidrera), bien lugares públicos y abiertos de la ciudad y cercanías (las Ramblas, el Barrio Chino-Raval, el monumento a Colón, la Plaza Real, las calles y pisos del -más imaginario que imaginado- barrio obrero de San Magín, San Andrés, Hospitalet, Sant Cugat, Sarrià-Sant Gervasi, etc.), bien incluso algunos espacios públicos -cerrados- de la gastronomía (la tienda de la calle Fernando [Carrer de Ferran] o los restaurantes Túnel y Casa Leopoldo).

Más allá de la primera función de localización, de coordenada topográfica, del espacio, la inclusión en esta ficción narrativa de lugares pertenecientes a la serie física real, externa y urbana, contribuye a crear un fuerte efecto de verosimilitud realista (Albaladejo, 1991: 103-104); Anderson (1985), por ejemplo, verificó esta cuestión identificando las 710 situaciones de Fortunata y Jacinta que se corresponden con ubicaciones reales madrileñas. $Y$, efectivamente, de una parte, concerniente a la dimensión semántica de la novela individualmente considerada, uno de los elementos fundamentales que sustentan las caracterizaciones críticas comunes de esta obra de Montalbán como novela realista es justamente

\footnotetext{
${ }^{8}$ La novela está formalmente organizada en secuencias integradas por distintas escenas $\mathrm{y}$, en cuanto a sus técnicas narrativas compositivas, hay que destacar la estructura unitaria y lineal básica de la acción y el mantenimiento de un orden temporal esencialmente cronológico y sucesivo, en respectiva coincidencia con la forma y el tiempo de la investigación de Carvalho. Frente a la idea de Padró (2018: 23-24) de que tanto el ciclo de Carvalho como este relato son novelas-collage, considero que no es esta en absoluto una técnica compositiva de la obra, en la que más bien podría hablarse de lo que acabo de indicar y, en todo caso y pensando en la reconstrucción del crimen por la investigación detectivesca, de lo que Baquero Goyanes (1989: 206-212), justamente en un capítulo titulado «Estructuras geométricas», llamaba arquitectura circular y veía propia y característica de la novela policiaca.
} 
esta recreación de lugares, ambientes, zonas, barrios, monumentos y otros marcadores topográficos ${ }^{9}$ de Barcelona -y proximidades-, que construyen el relato como semánticamente verosímil y epistémicamente creíble.

Y otra funcionalidad, tercera, de los lugares reside en su capacidad de semiotizarse y adquirir, en correlación con determinados códigos ideológicos o culturales y ciertas estrategias narrativas, un valor simbólico (Gullón, 1980: 25) capaz de remitir a tales códigos, bien en un funcionamiento conforme o al contrario crítico. Dicotomías como campo/ciudad, centro/periferia, arriba/abajo, público/privado, izquierda/derecha, dentro/fuera, lejos/cerca, etc. pueden connotar oposiciones axiológicas como acogedor/hostil, protección/indefensión, favorable/desfavorable (Lotman, 1973: 281) o, simplemente, aludir y simbolizar metáforas ideoculturales: por ejemplo, Cuesta Abad (1989) examina la vinculación de los espacios con la dialéctica refugio/prisión en Fortunata y Jacinta de Galdós y Palmieri (1988) estudia el funcionamiento de la oposición naturaleza/cultura en relación a los mundos de Cosimo y Biagio en Il barone rampante de Calvino. Hay a mi entender en el caso concreto de Los mares del surun triple eje de referencialidad ideocultural mediante oposiciones espaciales, siempre de forma crítica. Privado/público remite, como se ha visto, a los espacios vivenciales y particulares de Carvalho frente a los de uso común y general por la ciudadanía, pero también a los dos lados o caras que se atribuyen al sujeto-individuo en el sistema social vigente. Arriba/abajo, refiriéndose a la zona alta y baja de Barcelona (Vallvidrera, Sarrià-Sant Gervasi/las Ramblas, Barrio Chino-Raval, Barceloneta), y centro/periferia, distinguiendo el núcleo de la capital catalana de primordialmente los barrios obreros (Barcelona/*San Magín) e incluso de otras poblaciones próximas (San Andrés, Hospitalet, Sant Cugat), muestran conjuntamente, en un doble eje respectivamente vertical y horizontal, las también dobles contradicciones urbanas y demográficas, sociales y económicas, tanto de la urbe en particular como del sistema en su conjunto: los barrios como ámbitos urbanos separados de residencia de las clases sociales, su delimitación como brecha entre las mismas, las vías de comunicación más como fronteras difícilmente transitables que como

${ }^{9}$ Emplazamientos espaciales urbanos usualmente indicados, descritos o no, pero también frecuentemente solo sugeridos, o simplemente formulados de forma implícita narrativamente y deducibles mediante la cooperación interpretativa lectoral. 
integraciones -como demuestran los pasos ocasionales de Carvalho y el fracasado intento de desclasamiento y cambio de hábitat del financiero-. De este modo, la ciudad, Barcelona, trasciende su mapa urbano físico, topográfico, para postularse como un mapa cognitivo social en el sentido de Jameson (1988) -concepto que probablemente habría entusiasmado a Vázquez Montalbán-, representando en el espacio, a través de la intersección de la significación textual y la cooperación interpretativa lectoral, la complejidad de las relaciones sociourbanas en el sistema socioeconómico español de la etapa de la transición a la democracia ${ }^{10}$.

\subsection{La Barcelona de Carvalho. Desplazamientos: itinerarios y actuaciones}

El ámbito de actuación perfila no tanto un emplazamiento como una extensión situacional íntimamente unida al tiempo, actos y seres, una dimensión escénica tempoespacial que cubre -como en teatro- la entrada y salida de actores y la realización procesual de un acontecimiento por los mismos; sus límites son un desde dónde y cuándo y un hasta dónde y cuándo tiene lugar la escena narrativa (Valles, 2008: 192). Así, en la breve secuencia final del libro antes aludida, las cuatro situaciones topográficas -cocina, salón, jardín y sótano- de la casa de Vallvidrera del detective, se corresponden con un solo ámbito de actuación: el hogar de Carvalho desde la hora de la cena a las cinco de la mañana, cuando se despierta, en el que este único actor encuentra, entierra, se queja brevemente del degollamiento de su perrita pastor alemán y se emborracha. En esta fusión tempoespacial vinculada al proceso de realización de un acontecimiento y su ejecución/sufrimiento por uno o varios actores, Carvalho realiza distintos actos físicos externos (enciende el fuego, se calza las zapatillas, cocina para él y la perrita, la ve, cava un hoyo, deposita a la perra, recubre el hoyo, mira a la ciudad, bebe, [duerme], se despierta), internos (repara en que no está la perra, piensa que haya escapado, saltado el muro o quedado encerrada, siente ansiedad, se emociona, desea sollozar, se le humedecen los ojos, mira la ciudad, se desahoga, siente limpieza en el pecho, tiene hambre y sed), verbales (exclama un doble exabrupto general) o cinésicos y proxémicos (sale al jardín, busca a la perrita, la levanta, va al sótano, vuelve con una pala, deja caer varios objetos en la

${ }^{10}$ Véase el trabajo de Saval (2018) sobre el funcionamiento del Raval como espacio recordado y de luchas democráticas. 
fosa, tira la pala, se sienta en el muro, se aferra a los ladrillos, [retorna a la casa, se sienta a beber, va al dormitorio]), incluyendo en estos últimos no solo los gestos, movimientos y posiciones sino los desplazamientos e itinerarios por el espacio de su hogar por Carvalho: salón, cocina, salón, jardín, sótano, jardín, [salón], [dormitorio] (Vázquez Montalbán, 2018: 284-285).

Estos desplazamientos e itinerarios intraescénicos de los actores pueden serlo también interescénicos si afectan a distintos ámbitos de actuación y, en consecuencia, a parte o a toda la narración. Ya me he referido a la importancia del dinamismo y las rutas del detective por el entorno urbano en la novela negra y, en el caso de Los mares del sur, Padró (2018: 30-37) ha distinguido el itinerario de la víctima, Stuart Pedrell, de los tres ejes direccionales de movilidad del investigador, Pepe Carvalho.

El primero, el del financiero, que solo existe en el universo narrativo como trayecto reconstruido por la indagación detectivesca, baja desde la casa del Puntxet hasta el barrio obrero -supuesto- de San Magín y reasciende hasta la casa de su amante en Sant Gervasi para morir e ir a parar como cadáver a la Trinitat: un viaje de pretendido desclasamiento social y alejamiento vital tan fallido como su obsesiva pretensión de imitar el viaje de Gauguin a la Polinesia. Dos de los itinerarios de Carvalho, ambos de ida y vuelta, transitan simbólicamente, como ya se ha visto, entre la parte alta y baja de la ciudad: el primero es vital y cotidiano, y vincula su casa de Vallvidrera y el despacho de las Ramblas; el segundo es profesional y ocasional de la investigación, y va de la parte alta de Barcelona a la baja, volviendo de nuevo a las alturas -Sant Gervasi-* San Magín-Sarrià-, en clara correspondencia con la trayectoria detectivesca (encargorealización-fin de la investigación y respectivamente comisión-indagación-solución del crimen). Hay todavía un tercer eje de movilidad, más bien horizontal o transversal, que está vinculado tanto a las aficiones gastronómicas como a las cuestiones culturales ${ }^{11}$. En cuanto a lo primero, el detective deambula en la novela por las tiendas de comida de la calle Fernando, los restaurantes Túnel y Casa Leopoldo, la pensión próxima a la casa de Charo o el bar del Barrio Chino. Respecto a lo segundo, asiste a una mesa redonda sobre novela negra, repasa los libros de Pedrell y se

\footnotetext{
${ }^{11}$ Recetas gastronómicas y encuentros culturales metatextuales de Carvalho presentes en todo el ciclo.
} 
detiene en el poema Las islas de las Poesías completas de Cernuda, visita al pintor Artimbau y al erudito Sergio Beser -catedrático y amigo real del autor $^{12}-$, en este último caso buscando explicación a los versos de Salvatore Quasimodo (più nessuno mi porterà nel sud) que abren a modo de cornisa el libro en su dedicatoria y en cierto modo en el propio paratexto titular y que constituyen el objeto de deseo de desclasamiento social y escapada vital del financiero asesinado.

Estos cuatro itinerarios en total trazan un imaginario mapa físico, topográfico y de trayectorias, de la ciudad de Barcelona que pueden ser sin duda complementados por los mapas cognitivos (Ryan, 2003; Ryan, Foote y Azaryahu, 2016: 75-100) desarrollados por la actividad mental del lector. Ryan recoge los planteamientos de Jameson y otros estudiosos al respecto, ahonda en la dimensión individual del concepto de mapa cognitivo [espacial]como «un modelo mental de relaciones espaciales» $\mathrm{y}$ realiza un análisis, verificando la experimentación, en Crónica de una muerte anunciada de García Márquez. Y sin duda el estudio de cualquiera de los niveles de funcionamiento del espacio narrativo no puede ser separado de la dialéctica información/vacío textual y reconstrucción/construcción lectoral que cualquier estrategia lectora de implementación interpretativa por parte del lector implícito juega en estos casos. De hecho, las intervenciones del autor implícito (Booth, 1974) y del narrador, que son tanto más crecientes cuanto más nos acerquemos a la presentación y organización discursiva del espacio -al diseño espacialen el estrato del relato, son inversamente proporcionales a la necesidad de relleno de vacíos textuales, de aportación de imaginación y configuración de sentido por parte del lector implícito (Iser, 1987), creciente en cambio cuanto más nos aproximamos a la localización en el estrato de la fábula, que es donde más se manifiesta la indeterminación del espacio (Valles, 2008: 195), ese esquematismo que hace que no haya otro componente del texto narrativo «en que se configure un lector implícito más lleno de competencias que en el de la construcción de los espacios» (Villanueva, 1989: 43).

${ }^{12}$ De alguna forma, además de los guiños -como el anterior a su amigo-, todas estas referencias culturales se alinean -tanto en la serie como en esta obra en particular- con los frecuentes accesos al lirismo en un registro discursivo culto, que funciona como contrapunto dialógico de la presencia del lenguaje coloquial, los hechos truculentos y los acompañantes del detective y otros actores de baja extracción y cultura. 


\subsection{La Barcelona del relato: el diseño verbal y discursivo del espacio}

Finalmente, en relación con los códigos temporales, narrativos, focalizadores y las propias instancias intratextuales de autor y lector implícitos, el espacio se presenta y configura verbal y discursivamente (Gullón, 1980: 21; Valles, 2008: 194; Weisgerber, 1978: 10): los lugares y ámbitos de actuación se muestran y diseñan así como espacios. De forma directa, es esencial en esta operación constructiva el discurso del narrador, o bien secundariamente el del propio personaje, pues son sus voces y palabras las que modelan y transforman los lugares y ámbitos escénicos en espacios, pero también por su propia distancia, que ofrece unas posiciones respectivas de mayor cercanía o lejanía en los discursos miméticos, traspuestos o narrativizados (Genette, 1972: 191-193) que repercute asimismo en unas lógicas visiones del espacio más próximas y detallistas o más lejanas y globales (Bal, 1987: 107). Estas visiones tienen especial vinculación también con la focalización narrativa (Uspenski, 1973: 58-65; Weisgerber, 1978: 14-15), que percibe de forma distinta el espacio con distintas posibilidades: la de representar objetivamente lugares y objetos en la focalización externa, la de captar de forma cercana pero subjetiva y limitada los mismos en la focalización interna o de personaje -incluso contrastivamente si es variable y múltiple- o la de permitir la visión de cosas y sitios sin verlos o estar en ellos o bien de explorar la conciencia, pensamientos y emociones de los personajes ante el espacio en la focalización omnisciente. Y por último el diseño espacial se liga asimismo al tiempo, particularmente a la duración o cantidad, estableciendo paradas o pausas (Genette, 1972: 122-144) textuales en la fluencia cronológica e incluso disponiendo diversas acciones sincrónicamente, pero mostrándolas de forma yuxtapuesta y suprimiendo conectivos temporales de forma que se cree el efecto de una simultaneidad temporal y una acumulación espacial, lo que Frank (1981) llamó spatial form en 1945.

En Los mares del sur la preponderancia del modo narrativo frente al dramático o dialogado aporta distancia y lejanía del espacio, hasta el punto de que en ocasiones los lugares son verbal y explícitamente eliminados y deben ser deducidos y construidos mentalmente en la operación lectora: así ocurre por ejemplo en la última secuencia ya comentada, donde el esquematismo llega a eliminar el salón y el dormitorio que solo cabe deducir del acto de la bebida de una botella de orujo por Carvalho y que se despierte a las cinco de la madrugada. Esto se compensa no 
obstante con una visión omnisciente que permite hacer saber los pensamientos o sentimientos de personajes ante el espacio o, en ocasiones, incluso vincularlos, como ocurre triplemente, con la inquietud, el llanto y el enfado, en esa misma secuencia: «[...] una ansiedad oscura y progresivamente dolorosa le hizo buscarla por los rincones del jardín [...]», «La ciudad centelleaba a lo lejos, y sus luces empezaron a encharcarse en los ojos de Carvalho»; "mirando hacia la ciudad iluminada, dijo: -Hijos de puta, hijos de puta» (Vázquez Montalbán, 2018: 284-285). Como se ve, en esta narración Barcelona no es solo un lugar y un ámbito de actuación sino un espacio diseñado y construido con una gran trascendencia y simbolismo, tanto intra como extranarrativamente, tanto respecto a la historia y al universo novelesco como a la Historia y a la sociedad -urbanade la transición española a la democracia: «su desarrollo urbano, su guetización, la especulación urbana, son móviles de la acción. Su separación en barrios representa sobre el terreno una brecha social [...]» (Padró, 2018: 33).

De hecho, como se constata en las tres citas anteriores de la novela, espacio y personaje se relacionan estrechamente. En ciertas ocasiones el espacio se construye y diseña metonímicamente, a partir de uno de los rasgos o cualidades propias del personaje que lo habita o lo emplea, como vieron Gullón (1980: 49-51) o Bobes (1985: 196-216) al examinar, por ejemplo, las relaciones entre la visión desde la torre de la Catedral de Vetusta y la ambición de don Fermín en La Regenta de Clarín. En esta novela de Vázquez Montalbán se presentan estas conexiones en distintas ocasiones, pues Barcelona muestra en ella no solo «su geografía material» sino «[...] su geografía social y humana, su arqueología de conflictos, miserias, deseos y memorias» (Colmeiro, 1994: 56): las prostitutas que encuentra Carvalho paseando por las Ramblas al principio, e incluso la propia Charo, su pareja ocasional; la moderna casa en Sarrià de la moderna examante de la víctima, Lita; el lujoso despacho en la zona alta de Barcelona del rico abogado Viladecans; en cierta medida, incluso el propio despacho de Carvalho en las Ramblas tiene el tono algo abandonado y el aspecto algo añejo vinculado a la apariencia y la edad madura del propio detective: «Interrogaba a las paredes verdes de su despacho o a alguien supuestamente sentado más allá de su mesa de oficina años cuarenta, barnices suaves oscurecidos durante treinta años, como si 
hubieran estado siempre a remojo de aquella penumbra de despacho ramblero» (Vázquez Montalbán, 2018: 47).

Otras veces los espacios se impregnan de cargas negativas, o positivas, o adquieren valores securizantes o peligrosos, o constriñen o al revés ofrecen libertad al personaje: esto es, se semiotizan y convierten en atmósferas o ambientes determinados, en una dimensión de especial identificación con la psicología, actividad o sentimientos del personaje cuya topofilia estudió amplia y diversamente en 1957 Bachelard (1986): la casa, los cajones, los nidos y las conchas, la miniatura y la inmensidad, etc. En este sentido, frente al sentido protector que su casa y su despacho le ofrecen a Carvalho, el entorno urbano, la ciudad de Barcelona, es su espacio de investigación y, en consecuencia, pese a su cariño e identificación con determinados lugares exteriores o interiores -rincones, calles, tiendas, restaurantes, etc.-, más peligroso y hostil: las últimas palabras dichas impersonalmente a la ciudad al final de la novela y arriba reproducidas dan cuenta de su sentimiento final de dolor e ira hacia la misma, sus habitantes e injusticias.

Finalmente y en tercera instancia, referida a la captación sensorial del espacio por los personajes (Matoré, 1976), pese al papel ocasional pero iterativo que juegan el olfato y el gusto en todas las degustaciones y preparaciones culinarias y enológicas de Carvalho -las recetas-, siguen siendo la audición y la visión los elementos fundamentales de captación del espacio por el detective: la primera por lo que hace a las informaciones llegadas en los interrogatorios; la segunda porque la visión, o mejor la mirada, se convierte siempre en el principal elemento de escrutinio e investigación en los relatos detectivescos: la mirada escudriñadora y reveladora, detenida y atenta a los detalles...

Sin embargo, en lo relativo a la presentación y configuración del espacio es la descripción el elemento fundamental. Hamon (1981) ha estudiado en profundidad su contribución a la cohesión textual y la verosimilitud, su oscilación entre las formas económica y enumerativa (definición/catálogo), sus vinculaciones con otras disciplinas (urbanismo, geografía) y su organización como sistema jerarquizado de asociaciones (denominación/expansión, nomenclatura/predicación) y, basándose en él, Bal (1987: 134-140) ha distinguido la motivación de la descripción y 
diferenciado seis posibles modalidades ${ }^{13}$ de la última. No son acostumbradas ni en esta ni en otras novelas de la serie de Carvalho las descripciones profundas, minuciosas y objetivas; antes bien, los espacios -como los personajes- se presentan breve, subjetiva y valorativamente, mediados por la perspectiva omnisciente y la distancia de la narrativización y a veces tamizados por la valoración del autor implícito excusándose en el personaje o escudándose en el narrador; por ejemplo, la Vía Layetana, tras asociarse la comisaría a los tiempos franquistas predemocráticos y la propia calle al opuesto bullicio democrático de la mezcla de gentes, se perfila como «una calle de entreguerras, con el puerto en una punta y la Barcelona menestral de Gracia en la otra, artificialmente abierta para hacer circular el nervio comercial de la metrópoli y con el tiempo convertida en una calle de sindicatos y patronos, de policías y sus víctimas, más alguna Caja de Ahorros y el monumento entre jardines sobre fondo gotizante a uno de los condes más sólidos de Cataluña» (Vázquez Montalbán, 2018: 68). En ocasiones incluso, la brevedad y la subjetividad se vinculan y propulsan hacia el lirismo, como ocurre en la citada imagen de reflejo de las luces de la ciudad, nocturna y lejana, en los ojos lacrimosos de Carvalho (284) o se asocia espacio y morador, como sucede en el caso también citado del despacho ramblero del detective (47). No obstante, la función investigadora y la necesidad e importancia de la mirada a veces generan una descripción minuciosa y objetiva, enumerativa y casi enciclopédica, llena de expansiones y predicaciones -componentes y adjetivos- en términos de Hamon (1981); así ocurre cuando, antes de descubrir el poema de Quasimodo, Carvalho revisa el despacho preferido de la víctima, Stuart Pedrell, primero describiendo y repasando su mobiliario (Vázquez Montalbán, 2018: 64-65), luego revisando varios de sus

${ }^{13}$ Como ocurre con la caracterización del personaje, también en la descripción conviene tener en cuenta distintos aspectos que la determinan: el objeto (lugares/cosas, paisajes/escenarios, topografía/descripción), la perspectiva focal y la distancia (omnisciencia/equisciencia/infrasciencia, discurso mimético/traspuesto/narrativizado), la fuente narrativa (narrador/otro personaje/mismo personaje), el carácter de la información (objetivo/subjetivo, explícito/implícito, enunciado/inferido), la credibilidad (veraz/falso, creíble/dudoso/no creíble), la profundidad y penetración (simplicidad/complejidad, superficial/profunda), la forma y duración (en bloque/diseminada, circunstancial/permanente) o el criterio estético y el tono del diseño (realista/fantástico, surrealista/expresionista, serio/irónico, etc.). 
libros (65), por último y detenidamente, casi inventariando sus objetos de escritorio (66).

\section{CONCLUSIONES}

Más allá de las meras enunciaciones sobre la representación de la realidad social del espacio narrativo, he pretendido analizar aquí las estrategias narrativas concretas que utiliza al respecto una novela ejemplar como es Los mares del sur. a) el carácter absolutamente urbano, que acoge una dinámica de lógica narrativa actancial que vincula al desorden o injusticia y al crimen con el universo novelesco y enmarca la historia en una integración tempoespacial cronotópica que he denominado la jungla del asfalto en momentos de injusticia; b) la capacidad de simbolización del espacio tanto al trazar una correlación concreta entre los lugares privados individuales y la macrotopografía urbana con la micro y macrooorganización social y sus casi infranqueables fronteras -casas/ricos o pobres, barrios/clases-, como al emplear particularmente el valor simbólico e ideológico de ciertas posiciones y movimientos espaciales y al aplicar el concepto de mapa cognitivo social de Jameson; c) los desplazamientos intraescénicos -actos, posiciones y movimientos- y fundamentalmente interescénicos -itinerarios- de la víctima y sobre todo del investigador, Carvalho, entre los diferentes ámbitos actuacionales que conforman el entramado urbano y que refuerzan la interpretación anterior de la metáfora de la doble identidad, urbana y social, entre la estratificación y el desorden; d) finalmente, un diseño espacial del relato en el que no solo los elementos verbosimbólicos sino la narración externa y distanciada, la focalización omnisciente, el peso del narrador y del autor implícito contribuyen a construir un espacio descriptivamente bastante esquemático, simbólicamente muy representativo y discursivamente mostrado con un gran filtro de subjetividad (autor-narrador-investigador), incluso con algunos accesos al lirismo, en el que la mirada y el dinamismo del protagonista son respectivos ejes sensorial -mirada- y actuacional -investigación- de la relación con Barcelona y en que la asociación de espacios y personajes (casas y despachos, calles y zonas, etc.) se hace relativamente frecuente. 


\section{BIBLIOGRAFÍA CITADA}

Albaladejo, T. (1991): Semántica de la narración: la ficción realista. Madrid: Taurus.

ANDERSON, F. (1985): Espacio urbano y novela. Madrid en Fortunata y Jacinta. Madrid: José Porrúa.

BaChelard, G. (1986): La poética del espacio. México: FCE.

BAJTín, M. (1986): Problemas de la poética de Dostoievski. México: FCE.

BAJTín, M. (1989): Teoría y estética de la novela. Madrid, Taurus.

BAL, M. (1987): Teoría de la narrativa (una introducción a la narratología). Madrid: Cátedra.

BAlló, J. y PÉRez, X. (2005): Yo ya he estado aquí. Ficciones de la repetición. Barcelona: Anagrama.

BAQUeRo GoyaneS, M. (1989): Estructuras de la novela actual. Madrid: Castalia. BARTHES, R. (1980): $S / Z$. Madrid: Siglo XXI.

Bobes Naves, C. (1985): Teoría general de la novela. Semiología de La Regenta. Madrid: Gredos.

Bоотн, W. C. (1974): La retórica de la ficción. Barcelona: Antoni Bosch.

Colmeiro, J. F. (1994): La novela policiaca española: teoría e historia crítica. Barcelona: Ánthropos.

Conte, R. (1979): «La novela como pretexto». El País, 25 de noviembre.

Cuesta ABAD, J. M. (1989): «Los espacios de Fortunata. Dialéctica espacio-refugio/espacio-prisión». En Ávila, J. (ed.): Galdós. Centenario de Fortunata y Jacinta (1887-1987). Actas. Madrid: Universidad Complutense, 477-485.

FRANK, J. (1981): «Spatial Form: Thirty Years After». En Smitten, J. y Daghistany, A. (eds.): Spatial Form in Narrative. Ithaca-London: Cornell University Press, 202-243.

Genette, G. (1972): Figures III. Paris: Seuil.

GULLÓN, R. (1980): Espacio y novela. Barcelona: Antoni Bosch.

HAMON, Ph. (1981): Introduction à l'analyse du descriptif. Paris: Hachette.

ISER, W. (1987): El acto de leer. Teoría del efecto estético. Madrid: Taurus.

JAmeson, F. (1988): «Cognitive Mapping». En Cory, N. y Grossberg, L. (eds.): Marxism and the Interpretation of Culture. Urbana: University of Illinois Press, 347-360.

Lotman, I. M. (1973): La estructura del texto artístico. Madrid: Istmo.

Matoré, G. (1976): L'espace humain. L'expression de l'espace dans la vie, la pensé et l'art contemporains. Paris: Nizet. 
PADRó, B. (2018): «Estudio preliminar». En Vázquez Montalbán, M.: Los mares del sur. Barcelona: Austral, 6-36.

PALMIERI, P. (1988): «Il sistema spaziale de Il Barone Rampante». Lingua e Stile, $23.2,251-270$.

RYan, M. L. (2003): «Cognitive Maps and the Construction of Narrative Space». En Herman, D. (ed.): Narrative theory and the cognitive sciences. Stanford: CSLI Publications, 215-242.

Ryan, M. L., Foote, K. E. y AzARyahU, M. (2016): Narrating Space/Spatializing Narrative: Where Narrative theory and Geography Meet. Columbus: The Ohio State University Press.

SÁNChez ZAPATERo, J. y MARTín EscribÀ, À. (2017): Continuará... Sagas literarias en el género negro y policiaco español. Barcelona: Alrevés.

SAVAL, J. V. (2018): «El Raval de Barcelona según Manuel Vázquez Montalbán: espacio de la memoria, espacio de resistencia». En Sansano i Belso, G. (coord.): Silenci, oblit i preservació de la memòria democràtica: una aportació interdisciplinària. València-Castelló-Alacant, Universitat de ValènciaUniversitat Jaume I-Universitat d'Alacant, 180-188.

UsPENSKI, B. (1973): A Poetics of Composition. Berkeley: UCP.

VALLEs Calatrava, J. R. (1991): La novela criminal española. Granada: Universidad de Granada.

VAlles Calatrava, J. R. (2008): Teoría de la narrativa. Una perspectiva sistemática. Madrid-Frankfurt: Iberoamericana-Vervuert.

VÁzQuez de PARGa, S. (1981): Los mitos de la novela criminal. Barcelona: Planeta.

VÁzQuez Montalbán, M. (1974): Tatuaje. Barcelona: Los libros De la Frontera.

VÁZQuez Montalbán, M. (2004): Barcelonas. Barcelona: Península.

VÁzQuez Montalbán, M. (2018): Los mares del sur. Barcelona: Austral.

VILlANUEVA, D. (1989): El comentario de textos narrativos: la novela. Gijón-Valladolid: Júcar-Aceña.

WEISGERBER, J. (1978): L'espace romanesque. Lausanne: L'âge d'homme.

Zoran, G. (1984): «Towards a Theory of Space in Narrative». Poetics Today, 5, 309-335.

José R. VALLES-CALATRAVA

Universidad de Almería jrvalles@ual.es

https://orcid.org/0000-0003-2761-8452 
